\title{
DETERMINATION OF THE BIOBASED CONTENT IN PLASTICS BY RADIOCARBON
}

\author{
Gianluca Quarta ${ }^{1,2} \bullet$ Lucio Calcagnile $^{1} \bullet$ Massimo Giffoni $^{3} \bullet$ Eugenia Braione $^{1} \bullet$ Marisa D’Elia $^{1}$
}

ABSTRACT. Accelerator mass spectrometry (AMS) radiocarbon analyses were performed on biobased unsaturated polyester resins in order to assess the potential of the method for the determination of the bio-fraction. Different resins were synthesized in the laboratory with different proportions of raw materials of biogenic origin, and analyzed both in the liquid and in the solid form. As a preliminary step of the study, both the biobased and the fossil-derived raw materials were analyzed in order to determine their ${ }^{14} \mathrm{C}$ content. A comparison of the obtained results with the expected ones allowed us to investigate the potential of the ${ }^{14} \mathrm{C}$ method in this field as well as to address some still open issues such as the levels of uncertainty and accuracy as related to the calculation procedures, the correction for isotopic fractionation, and the effect of the presence of volatile components in the analyzed materials.

\section{INTRODUCTION}

Due to the need for reducing $\mathrm{CO}_{2}$ emissions into the atmosphere, international protocols have been introduced that aim to promote the use of products of biogenic origin, which have assimilated $\mathrm{CO}_{2}$ from the atmosphere during their life, thus no fossil resource is mobilized. The development of fast, accurate, and reliable experimental methods for determining the bio-fraction in carbon-based industrial products such as bio-polymers is thus an active research field. The use of the radiocarbon dating method for this purpose is based on the large difference in ${ }^{14} \mathrm{C}$ isotopic signature between the fossilderived $\left({ }^{14} \mathrm{C}\right.$-free) and the biogenic component of $\mathrm{C}$-based materials, whose ${ }^{14} \mathrm{C}$ content reflects, in a first approximation, modern ${ }^{14} \mathrm{C}$ atmospheric levels. In fact, the use of ${ }^{14} \mathrm{C}$ for the determination of the biobased content in different kinds of products such as fuels (Dijs et al. 2006), polymers (Onishi at al. 2010), and flue gases from industrial sources (Calcagnile et al. 2011) has been widely reported, mainly in recent years, in scientific literature and formally defined in the United Stated by the ASTM Method D6866 (ASTM International 2010). Although the method is quite easy in its basic principle, several aspects make its real application difficult. Among these aspects is the effect of the decreasing (currently with a rate of about $0.006 \mathrm{Fm}$ per year) ${ }^{14} \mathrm{C}$ concentration in the modern atmosphere as a result of atomic bomb testing (Levin and Kromer 2004). The possible evaporation of volatile components has to be accounted for as well. Previous studies have addressed these issues by comparing different experimental approaches (benzene synthesis followed by liquid scintillation counting, accelerator mass spectrometry [AMS], and $\mathrm{CO}_{2}$ absorption) for ${ }^{14} \mathrm{C}$ content determination in different products (Norton and Devlin 2006) and have assessed the accuracy achievable by the method (Norton et al. 2007). Due to the above-mentioned sources of uncertainty, the final precision achievable by the method is about $3 \%$ (absolute), significantly higher than the instrument uncertainty associated with the ${ }^{14} \mathrm{C}$ concentration determination which is, at least by AMS, routinely of about $0.3-0.5 \%$. Nevertheless, the achievable level of uncertainty is acceptable in most of the industrial applications, especially considering the fact that the ${ }^{14} \mathrm{C}$ method is the only technique that can be employed to experimentally determine the bio-derived fraction.

In the polymer industry, an interest exists in the possible use of this approach as a fast and reliable protocol for assessment of the "biobased" content at different stages of the industrial process, such as the control of the raw materials, the optimization of the synthesis process, the certification of ready-to-market products, as well as the control of the bio-content in products already on the market.

${ }^{1}$ CEDAD-Department of Engineering for Innovation, University of Salento, Via per Monteroni, 73100 Lecce, Italy.

${ }^{2}$ Corresponding author. Email: gianluca.quarta@unisalento.it.

${ }^{3}$ Polynt S.p.A., Via del Pruneto 40, 52027, San Giovanni Valdarno (AR), Italy.

(c) 2013 by the Arizona Board of Regents on behalf of the University of Arizona

Proceedings of the 21st International Radiocarbon Conference edited by A J T Jull \& C Hatté

RADIOCARBON, Vol 55, Nr 2-3, 2013, p 1834-1844 


\section{G Quarta et al.}

This article focuses on the analysis of a particular class of polymeric materials: unsaturated polyester resins (UPR). UPR are one of the most important thermoset materials, widely used for the production of composite materials such as fiber-reinforced plastics. The easy processing of these materials explains their wide use in different fields of application such as in the automotive, construction, and marine industries (Penczek et al. 2005). UPR are usually synthesized through polycondensation reactions between dibasic acids or anhydrides, such as maleic anhydride, and glycols. A monomer (usually styrene) is then added to the polymer in order to set the polymer viscosity. The monomer is also used to cure the resin by initiating the crosslinking reaction between the molecular chains of the polymer along with the addition of a proper initiator such as MEKP (methyl ethyl ketone peroxide) and an accelerator such as a cobalt salt. A solid resin is thus obtained with higher mechanical properties. Until recently, all the raw materials used in the synthesis of UPR were entirely petroleumderived. Nevertheless, concern about environmental sustainability of human activities and the rising petroleum costs have triggered efforts for the use of renewable raw materials for the synthesis of UPR resins. In fact, the first UPR with a bio-content of 18\% appeared on the market in 2003 (Andjelkovic et al. 2009). Since then, the industrial interest in the development of biobased UPRs has significantly grown with large efforts dedicated to enhancing the bio-fraction and at the same time, the performance requirements in terms, of mechanical, physical, and thermal properties.

In recent years, research efforts have been devoted by Polynt S.p.a. to developing biobased UPRs and a collaboration has been established with CEDAD (Centre for Dating and Diagnostics), University of Salento for the assessment of the biobased content using the ${ }^{14} \mathrm{C}$ method. As a first step of this collaboration, the results of which are presented here, a study was carried out in order to assess the advantages and drawbacks of this approach in addressing the achievable precision and accuracy. For this purpose, different polyester resins were produced with different expected bio-content and submitted to ${ }^{14} \mathrm{C}$ analyses. All the raw materials, both the fully bio and the fossil ones, employed in the synthesis were analyzed in order to define their ${ }^{14} \mathrm{C}$ content. Furthermore, the analyses included sampling the resins both in the liquid and solid forms, after the catalytic curing process. The results demonstrate overall the high reliability of the method but have also highlighted different crucial aspects, both during the synthesis process and the ${ }^{14} \mathrm{C}$ determination, whose underestimation can significantly degrade the accuracy of the results, leading to erroneous determinations and divergences between the expected and the measured bio-contents.

\section{METHODS}

Unsaturated polyester resins were synthesized at the R\&D laboratories of Polynt S.p.a. and samples for the ${ }^{14} \mathrm{C}$ analyses were taken from resins both in the liquid, before the curing process, and in the solid forms. Liquid resins were synthesized by using as biogenic raw materials monoprolylene glycol (MPG) and an organic acid. These 2 commercially available biogenic materials had a certified bio-content of $100 \%$ and were both obtained from corn glucose from China. Fully fossil styrene was then added to the liquid resins as already mentioned. Solid resins were obtained by adding, to the liquid resins, MEKP (Methyl Ethyl Ketone Peroxide) as initiator of the crosslinking reaction and cobalt octoate as accelerator. Both the initiator and the accelerator were expected to be fully fossil materials. Table 1 lists all the samples submitted for ${ }^{14} \mathrm{C}$ analysis including solids, liquids, and the employed raw materials (both the expected fully biogenic and the fossil ones) together with a standard UPR routinely produced at the industrial scale by Polynt and containing only fossil carbon sources. The reason for analyzing also the "pure" materials was essentially to assess the fully biogenic origin of the bio-materials. Concerning the resins, for 4 of them (UPR A, D, F, and G in Table 1) ${ }^{14} \mathrm{C}$ analysis was carried out both on the liquid and on the solid. For all the prepared resins, the expected bio-content was then calculated by taking into account the composition of the prepared 
mixture and the bio-content of each component. The quantity that is determined by ${ }^{14} \mathrm{C}$ method is the fraction of biogenic origin of the total organic carbon contained in the sample (Norton and Devlin 2006). This quantity (\%bio) was calculated for all the prepared resins by using the following equation:

$$
\text { \%bio }=\frac{\sum_{i=1}^{N} N_{i} \chi_{i}}{\sum_{i=1}^{N} N_{i} \chi_{i}+\sum_{j=1}^{P} N_{j} \chi_{j}}
$$

where $\chi_{\mathrm{i}}$ and $\mathrm{N}_{\mathrm{i}}$ indicate the molar fraction and the number of carbon atoms contained in each of the $\mathrm{N}$ compounds of biogenic origin into the mixture, while $\chi_{\mathrm{j}}$ and $\mathrm{N}_{\mathrm{j}}$ are the corresponding quantities for the $\mathrm{P}$ compounds of fossil origin. As an example, for a liquid unsaturated polyester resin containing $35 \%$ by weight of styrene (and the remaining $65 \%$ by weight formed by MPG and the organic acid both of biogenic origin) the expected biogenic fraction of the total organic carbon is $49 \%$. It is worth noting that for the calculation of the bio-fraction of the solid resins also the presence of the organic catalyst (added in concentration of $1-2 \% \mathrm{vol}$ ) for the curing reaction has to be considered. The expected bio-fraction for all the synthesized resins is indicated in Table 1. We also underline that the expected bio-fractions indicated in Table 1 were calculated without considering the possible evaporation of styrene. Indeed, styrene is a volatile component and its evaporation can lead to an increase in bio-fraction. In fact, the presence of volatile components is surely a significant source of uncertainty in the method as already highlighted by Norton et al. (2007). The effect of styrene evaporation on the expected bio-fractions was thus estimated by using a value for the evaporation rate of styrene of $\sim 120 \mathrm{~g} / \mathrm{m}^{2}$ in $120 \mathrm{~min}$ at $25^{\circ} \mathrm{C}$ as determined by Polynt by weighting UPR samples in a ventilated test cell where a constant air flow with a speed of $0.5 \mathrm{~m} / \mathrm{s}$ was maintained during the tests. In this way, an average evaporation of $\sim 3 \%$ of the styrene content was estimated, which would result in a variation of the order of $2 \%$ in the expected bio-content as calculated by Equation 1 . In order to take into account this effect, for the calculated bio-fraction listed in Table 1 an uncertainty of $\sim 2 \%$ (absolute) was considered.

\section{AMS Sample Preparation and Measurement}

The selected samples were prepared for AMS ${ }^{14} \mathrm{C}$ determination that was carried out at CEDAD, University of Salento (Calcagnile et al. 2004a,b). About $5 \mathrm{mg}$ or $5 \mu \mathrm{L}$ were sampled from the solid and liquid samples, respectively. For the solid samples, the only pretreatment consisted in cleaning of the external surfaces with ethanol. The selected material was then sealed under vacuum in quartz tubes together with copper oxide and silver wool and combusted at $900{ }^{\circ} \mathrm{C}$ for $8 \mathrm{hr}$ in a muffle oven. The produced carbon dioxide was released by cracking the quartz tubes under vacuum and cryogenically purified before being reduced to graphite. The reduction to graphite was obtained at $600{ }^{\circ} \mathrm{C}$ through a catalytic reaction using $\mathrm{H}_{2}$ as the reducing agent and iron powder as catalyst. The extracted graphite was then pressed in the aluminium target holders and placed in the accelerator's ion source and the carbon isotopic ratios $\left({ }^{14} \mathrm{C} /{ }^{12} \mathrm{C}\right.$ and ${ }^{13} \mathrm{C} /{ }^{12} \mathrm{C}$ ) were determined by AMS (Calcagnile et al. 2005).

\section{Calculation of the Bio-Fraction}

Calculation of the bio-fraction of the total organic carbon in the analyzed products can be carried out by assuming a 2-component model with 2 sources of carbon: a bio-fraction $\mathrm{x}_{\text {bio }}$ with a ${ }^{14} \mathrm{C}$ concen- 


\section{G Quarta et al.}

Table 1 Summary of the samples and the corresponding expected bio-content.

\begin{tabular}{lll}
\hline Sample material & Status & Expected bio-content \\
\hline MPG & Liquid & $100 \%$ \\
MPG & Liquid & $100 \%$ \\
MPG & Liquid & $100 \%$ \\
Organic acid & Solid & $100 \%$ \\
Organic acid & Solid & $100 \%$ \\
Organic acid & Solid & $100 \%$ \\
MEKP & Liquid & $0 \%$ \\
Cobalt octoate & Liquid & $0 \%$ \\
UPR-A & Solid & $0 \%$ \\
UPR-A & Liquid & $0 \%$ \\
UPR-B & Solid & $7 \pm 1 \%$ \\
UPR-C & Solid & $34 \pm 1 \%$ \\
UPR-D & Solid & $49 \pm 2 \%$ \\
UPR-D & Liquid & $50 \pm 2 \%$ \\
UPR-E & Solid & $49 \pm 2 \%$ \\
UPR-F & Solid & $49 \pm 2 \%$ \\
UPR-F & Liquid & $50 \pm 2 \%$ \\
UPR-G & Solid & $49 \pm 2 \%$ \\
UPR-G & Liquid & $50 \pm 2 \%$ \\
\hline
\end{tabular}

tration of $\mathrm{f}_{\text {bio }}$ and a fossil fraction $\mathrm{x}_{\text {foss }}$ with a ${ }^{14} \mathrm{C}$ concentration $\mathrm{f}_{\text {foss }}$. In this way, the measured ${ }^{14} \mathrm{C}$ concentration in the sample $\mathrm{f}_{\text {meas }}$ can be written using the following isotopic mass balance equation:

$$
\mathrm{f}_{\text {meas }}=\mathrm{x}_{\text {bio }} \mathrm{f}_{\text {bio }}+\mathrm{x}_{\text {foss }} \mathrm{f}_{\text {foss }}
$$

which, in the hypothesis that the fossil component is fully depleted in its ${ }^{14} \mathrm{C}$ content $\left(f_{\text {foss }}=0\right.$ ), can be rearranged to calculate the bio-fraction as:

$$
\mathrm{x}_{\text {bio }}=\frac{\mathrm{f}_{\text {meas }}}{\mathrm{f}_{\text {bio }}}
$$

The actual application of this formula, which is indeed very simple in its formulation, hides some issues that have to be properly addressed. The first problem is related to the exact value of the $f_{\text {bio }}$ term, which represents the ${ }^{14} \mathrm{C}$ concentration in the fully biogenic component of the analyzed material. If we assume that this fraction is obtained from short-lived vegetation (as is the case of the present study since the MPG and organic acid are obtained from glucose extracted from corn), its value reflects the atmospheric ${ }^{14} \mathrm{C}$ concentration in the year and in the place of growth. This means that the $\mathrm{f}_{\text {bio }}$ term changes over the time following the well-known "bomb ${ }^{14} \mathrm{C}$ spike" and can be at the same time influenced by local dilution or enrichment effects, of natural or anthropogenic origin. The dependence of the $\mathrm{f}_{\text {bio }}$ term on the time of growth and on local effects means, in fact, that the ${ }^{14} \mathrm{C}$ atmospheric concentration should be known in the growing year and in the place of growth. This is, of course, hardly possible and the real application of Equation 3, a reference value for the $\mathrm{f}_{\text {bio }}$ term, has to be assumed by referring to the global curve expressing the declining atmospheric ${ }^{14} \mathrm{C}$ concentration. It is worth noting that the uncertainty associated with the proper value to assign to the $f_{\text {bio }}$ surely affects the real uncertainty associated with the $\mathrm{x}_{\text {bio }}$ determination. Typically, the uncertainty associated with $\mathrm{f}_{\text {bio }}$ is about $1-3 \%$ (absolute, $1 \sigma$ confidence level), thus significantly higher than the uncertainty due to the instrumental measurement of the $\mathrm{f}_{\text {meas }}$ term, which is about $0.3-0.5 \%$. 


\section{Calculation of the Bio-Fraction: Mass Fractionation Correction}

The $f_{\text {meas }}$ term contained in Equation 3 has to be properly corrected for isotopic fractionation as already pointed out by Norton and Devlin (2006). Not correcting for isotopic fractionation can in fact add another, unnecessary, source of uncertainty in the biogenic determination, which, in the case of corn-based products, can be $\sim 2 \%$. The correction for isotopic fractionation can be obtained by using the well-established equation of Mook and van der Plicht (1999):

$$
f_{\text {meas }}=f_{\text {meas }}^{\text {unc }}\left[\frac{1+\delta^{13} C_{N}}{1+\delta^{13} \mathrm{C}}\right]^{2}
$$

where $\mathrm{f}_{\text {meas }}$ and $\mathrm{f}_{\text {meas }}^{\text {unc }}$ indicate the values corrected and uncorrected for isotopic fractionation, $\delta^{13} C_{N}=-25 \%$, and $\delta^{13} \mathrm{C}$ refers to the analyzed samples. Nevertheless, we note that only the fraction of the samples (i.e. the biogenic component) containing ${ }^{14} \mathrm{C}$ should be corrected for isotopic fractionation by using Equation 4. In fact, only the content of ${ }^{14} \mathrm{C}$ in this fraction has been altered by isotope fractionation and should be thus corrected.

In the case of biobased polymers, this means that the correction for isotopic fractionation should be applied only to the fraction of biogenic origin by using the corresponding value of the $\delta^{13} \mathrm{C}$ term. In formulas, this means that the proper correction for isotopic fractionation should be carried out by using Equation 4 with $\delta^{13} \mathrm{C}=\delta^{13} \mathrm{C}_{\text {bio }}$ where $\delta^{13} \mathrm{C}_{\text {bio }}$ refers to the value corresponding to the bio-fraction in the analyzed materials. We can also note that the measured $\delta^{13} \mathrm{C}$ term is related to the $\delta^{13} \mathrm{C}_{\text {bio }}$ term by the following equation:

$$
\delta^{13} C=x_{b i o} \delta^{13} C_{b i o}+x_{f o s s} \delta^{13} C_{\text {foss }}
$$

from which one can easily see that when the $\delta^{13} \mathrm{C}_{\text {bio }}$ and $\delta^{13} \mathrm{C}_{\text {foss }}$ terms are different, the measured $\delta^{13} \mathrm{C}$ for the whole sample will be significantly different from the $\delta^{13} \mathrm{C}_{\text {bio }}$ term. This means that the use of the $\delta^{13} \mathrm{C}$ term measured on the whole material for mass fractionation correction is not correct.

This issue has been already highlighted by other authors in the analysis of samples containing carbon from bio and fossil sources such as the carbonate of terrestrial gastropods (Pigati 2002) or atmospheric $\mathrm{CO}_{2}$ (Mook 1980). More recently the same effect has been demonstrated by a dedicated experiment carried out by measuring mixtures of bio- and fossil-derived gases (Palstra and Meijer 2012).

The effect on the overall accuracy of the correction for mass fractionation is represented in Figure 1, which shows the error introduced in the determination of the bio-fraction as a function of the biobased content in the analyzed material. The $\delta^{13} \mathrm{C}$ value for the fossil component is taken to be $-35 \%$. The figure shows that the effect is greatest for bio-contents $\sim 50 \%$ and is larger when the bio-fraction is derived from plants with a $\mathrm{C}_{4}$ photosynthetic pathway, since the difference in the stable isotopic signature between the fossil and the bio-fraction is larger. It should be noted that the deviation from the true value introduced by the wrong fractionation correction can be as large as $1 \%$. The effect is indeed lower when the bio-fraction is derived from plants with $\mathrm{C}_{3}$ photosynthetic pathways and can induce inaccuracies of $\sim 0.5 \%$. The need to use the proper correction procedure for mass fractionation means, in the real application of the method, that the isotopic signature of the biogenic or the fossil fraction should be independently known. In the present study, in order to apply the proper mass fractionation procedure, the biogenic raw materials were analyzed and their carbon stable isotopic signature determined. When this is not possible, for instance when the ${ }^{14} \mathrm{C}$ method is used to 


\section{G Quarta et al.}

determine the bio-fraction in materials for which the employed raw materials are not known, the correction for mass fractionation has to be seen as a further source of uncertainty.

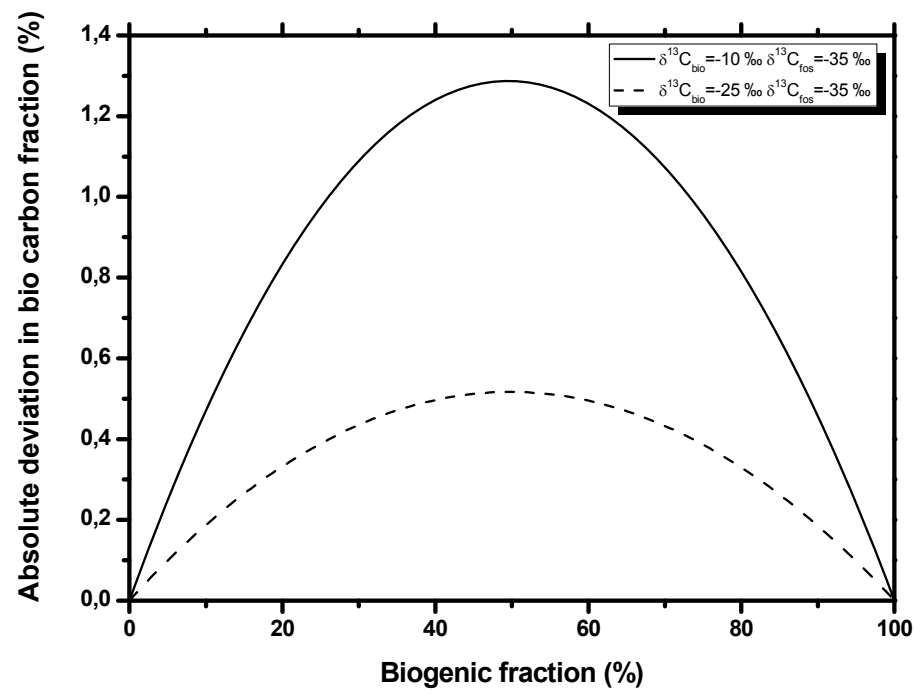

Figure 1 Deviation of the calculated bio-fraction from the true value induced by the wrong correction for mass fractionation (see text for details).

\section{RESULTS AND DISCUSSIONS}

The results of AMS ${ }^{14} \mathrm{C}$ determinations obtained for the raw materials, both fully biogenic and fossil, are given in Table 2 where the ${ }^{14} \mathrm{C}$ concentrations are expressed as ${ }^{14} \mathrm{a}$ values as defined by Mook and van der Plicht (1999). The measured ${ }^{14} \mathrm{C}$ concentrations for the fully biogenic materials were corrected for isotopic fractionation by using the $\delta^{13} \mathrm{C}$ term measured by AMS and expressed as ${ }^{14} \mathrm{a}_{\mathrm{N}}$, while the values measured for the fully fossil materials were not corrected for isotopic mass fractionation for the reasons previously discussed and are expressed as ${ }^{14} \mathrm{a}$ in Table 2.

Table $2{ }^{14} \mathrm{C}$ concentrations and $\delta^{13} \mathrm{C}$ values measured on fully biogenic and fully fossil materials.

\begin{tabular}{llr}
\hline Sample material & ${ }^{14} \mathrm{a}_{\mathrm{N}}$ or ${ }^{14} \mathrm{a}$ & \multicolumn{1}{c}{$\delta^{13} \mathrm{C}(\%)$} \\
\hline MPG & ${ }^{14} \mathrm{a}_{\mathrm{N}}=106.0 \pm 0.5 \%$ & $-9.5 \pm 0.2$ \\
MPG & ${ }^{14} \mathrm{a}_{\mathrm{N}}=105.2 \pm 0.6 \%$ & $-12.1 \pm 0.7$ \\
Organic acid & ${ }^{14} \mathrm{a}_{\mathrm{N}}=102.5 \pm 0.6 \%$ & $-11.3 \pm 0.4$ \\
Organic acid & ${ }^{14} \mathrm{a}_{\mathrm{N}}=101.6 \pm 0.5 \%$ & $-9.8 \pm 0.3$ \\
Organic acid & ${ }^{14} \mathrm{a}_{\mathrm{N}}=102.2 \pm 0.5 \%$ & $-9.6 \pm 0.4$ \\
MEKP & ${ }^{14} \mathrm{a}=0.35 \pm 0.03 \%$ & $-35.9 \pm 0.5$ \\
Cobalt octoate & ${ }^{14} \mathrm{a}=0.28 \pm 0.03 \%$ & $-35.9 \pm 0.5$ \\
\hline
\end{tabular}

The results obtained for MEKP and cobalt octoate are essentially indistinguishable from the overall background usually measured at CEDAD (Calcagnile at al. 2005) and confirm their full fossil origin. The results obtained for the fully biogenic materials are shown in Figure 2 where the value of $104.6 \pm 1.2$ corresponding to the $2009{ }^{14} \mathrm{C}$ atmospheric concentration as determined by Norton (2011) is reported for comparison. For the MPG and the organic acid, the average ${ }^{14} \mathrm{C}$ concentrations 
were $105.59 \pm 0.40$ and $102.08 \pm 0.40$. The value measured for MPG is thus consistent at the $1 \sigma$ level with the 2009 value of $104.6 \pm 1.2$ (Norton 2001), while the values measured for the organic acid are significantly lower, with a difference of $\sim 2.5 \sigma$. This difference can be explained by the presence of sources of fossil carbon in the production process or by local depletion effects of the atmospheric ${ }^{14} \mathrm{C}$ concentration in the growing place from industrial sources. Important information can also be obtained by looking at the $\delta^{13} \mathrm{C}$ data. In fact, even if the values reported in Table 2 have been determined by AMS with all the known associated limitations (Quarta et al. 2004), the measured values range from -12.1 to $-9.5 \%$, which are values typical of plants with a $\mathrm{C}_{4}$ photosynthetic pathways. In fact, the average value of $-10.5 \pm 1.0 \%$ is fully consistent with the $\delta^{13} \mathrm{C}$ values of -10.68 and $-10.22 \%$ measured, respectively, for corn starch and syrup (Jahren et al. 2006).

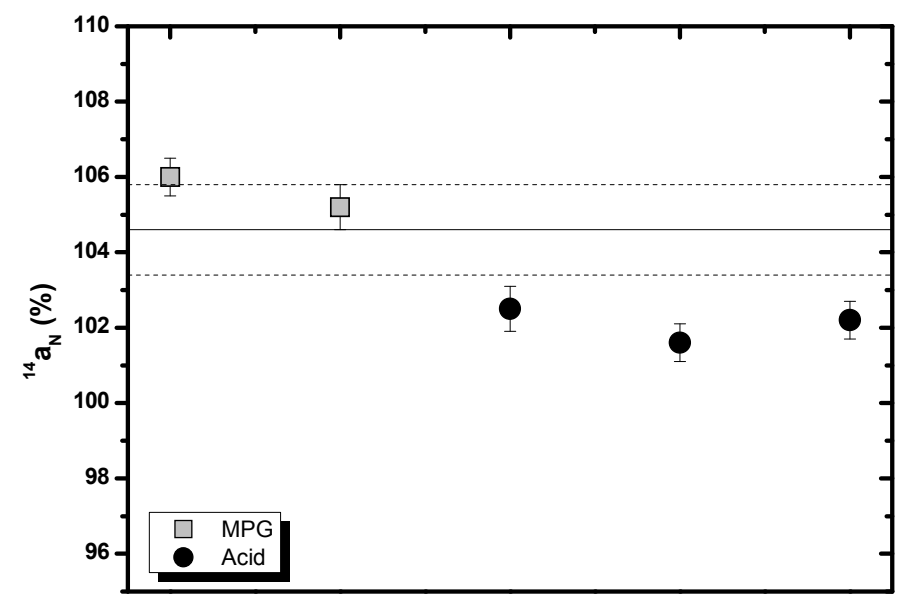

Figure 2 Radiocarbon concentration measured for the pure biogenic materials

${ }^{14} \mathrm{C}$ analysis results carried out on the resins are given in Table 3 for both the liquid and solid resins. For all the analyzed samples, except for the fully fossil resin for which no correction was performed, the correction for isotopic fractionation was carried out by using the average value of $-10.5 \%$ measured for the fully biogenic materials. The bio-fraction was then calculated by using Equation 3 with a value of $104.6 \pm 1.2$ for the $f_{\text {bio }}$ term. In order to check the agreement between the measured and the expected bio-content, the difference between these 2 values was calculated and divided by the sum of the corresponding $1 \sigma$ uncertainties. The results indicate that all the calculated bio-fractions agree with the expected ones within $2 \sigma$ as shown in Table 3 . The discussion about the results obtained for the liquid samples for the resins $\mathrm{F}$ and $\mathrm{G}$ is reported in the following. It can be also noted that the difference between measured-expected is positive for all the analyzed samples except for sample C-solid, with the measured value always larger than the expected one. We think this can be explained by the evaporation of styrene (discussed below). Figure 3 shows the correlation between the expected and measured bio-fraction $\left(r^{2}=0.99\right)$ for the solid unsaturated polyester resins with the 1:1 line shown for comparison.

A further analysis of the results was carried out by plotting the measured ${ }^{14} \mathrm{C}$ concentration versus the expected bio-content for the solid resins and for the fully biogenic raw materials. The results are given in Figure 4 where the line represents the linear fit of the data $\left(r^{2}=0.99\right)$. Thus, the best fit of the data is obtained by the function:

$$
\mathrm{f}_{\text {meas }}=(104.3 \pm 1.6) \mathrm{X}_{\text {bio }}+(0.25 \pm 0.24)
$$




\section{G Quarta et al.}

Table 3 Results of AMS analyses carried out on the unsaturated polyester resins.

\begin{tabular}{lcllll}
\hline Resin & $\begin{array}{l}\text { Bio-content } \\
\text { (expected) }\end{array}$ & ${ }^{14} \mathrm{a}_{\mathrm{N}}$ or ${ }^{14} \mathrm{a}$ & $\begin{array}{l}\delta^{13} \mathrm{C} \\
(\%)\end{array}$ & $\begin{array}{l}\text { Bio-content } \\
\text { (measured) }\end{array}$ & $\begin{array}{l}\text { Difference } \\
(\sigma \text { units })\end{array}$ \\
\hline A-Solid & $0 \%$ & $14 \mathrm{a}_{1}=0.28 \pm 0.03 \%$ & $-35.9 \pm 0.5$ & $0 \%$ & 0 \\
A-Liquid & $0 \%$ & $14 \mathrm{a}=0.25 \pm 0.03 \%$ & $-33.2 \pm 0.5$ & $0 \%$ & 0 \\
B-Solid & $7 \pm 1 \%$ & $14 \mathrm{a}_{\mathrm{N}}=7.2 \pm 0.1 \%$ & $-29.6 \pm 0.5$ & $7 \pm 1 \%$ & 0 \\
C-Solid & $34 \pm 1 \%$ & $14 \mathrm{a}_{\mathrm{N}}=32.9 \pm 0.2 \%$ & $-25.6 \pm 0.5$ & $32 \pm 1 \%$ & 1 \\
D-Solid & $49 \pm 2 \%$ & $14 \mathrm{a}_{\mathrm{N}}=51.7 \pm 0.3 \%$ & $-18.3 \pm 0.3$ & $49 \pm 1 \%$ & 0 \\
D-Liquid & $50 \pm 2 \%$ & $1 \mathrm{a}_{\mathrm{N}}=52.1 \pm 0.3 \%$ & $-17.4 \pm 0.4$ & $50 \pm 1 \%$ & 0 \\
E-Solid & $49 \pm 2 \%$ & ${ }^{14} \mathrm{a}_{\mathrm{N}}=55.3 \pm 0.4 \%$ & $-19.1 \pm 0.5$ & $53 \pm 1 \%$ & 1.5 \\
F-Solid & $49 \pm 2 \%$ & ${ }^{14} \mathrm{a}_{\mathrm{N}}=56.9 \pm 0.3 \%$ & $-19.6 \pm 0.1$ & $54 \pm 1 \%$ & 1.7 \\
F-Liquid & $50 \pm 2 \%$ & ${ }^{14} \mathrm{a}_{\mathrm{N}}=77.2 \pm 0.4 \%$ & $-22.2 \pm 0.5$ & $74 \pm 1 \%$ & - \\
G-Solid & $49 \pm 2 \%$ & $14_{\mathrm{N}}=53.3 \pm 0.4 \%$ & $-22.6 \pm 0.5$ & $51 \pm 1 \%$ & 0.7 \\
G-Liquid & $50 \pm 2 \%$ & $14 \mathrm{a}_{\mathrm{N}}=63.5 \pm 0.6 \%$ & $-21.6 \pm 0.5$ & $61 \pm 1 \%$ & - \\
\hline
\end{tabular}

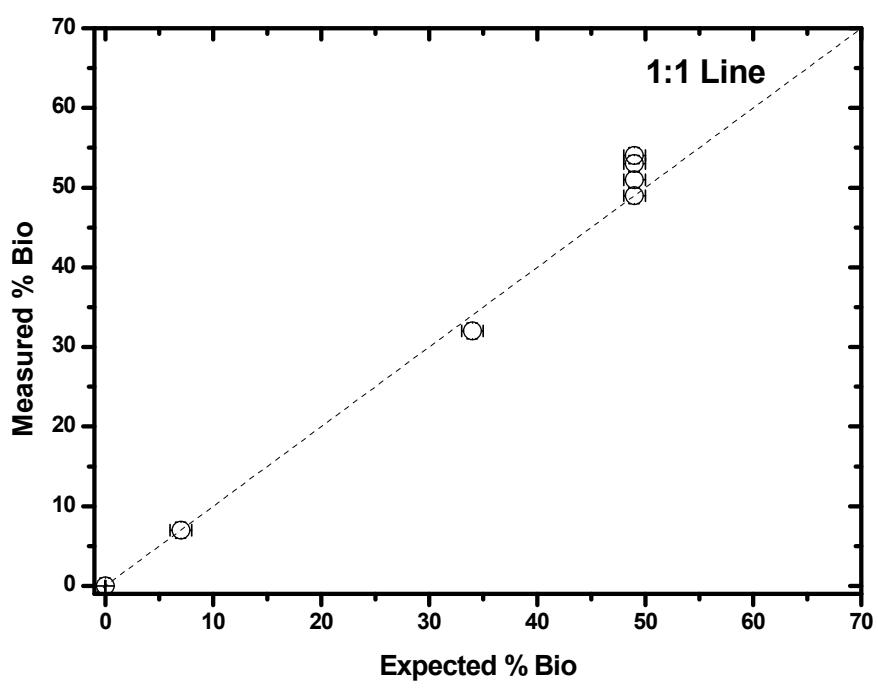

Figure 3 Correlation between the expected and measured bio-content in the solid resins.

We can now note, by comparison with Equation 3, that the slope of this curve represents the value of the $\mathrm{f}_{\mathrm{bio}}$ term that best fits the data. In our case, we then obtain $\mathrm{f}_{\mathrm{bio}}^{\mathrm{exp}}=104.3 \pm 1.6$, which is consistent with the value obtained by Norton (2011) of $104.6 \pm 1.2 \%$. A linear regression analysis of the data given in Figure 4 allows also to estimate a $\sim 3 \%$ level of uncertainty achievable by the method.

More complex is the analysis of the data obtained on the resins in liquid form. For 4 resins, the analyses were carried out on both the liquid and the solid resins. As given in Table 1, the difference in terms of bio-content between the same resin in the solid and liquid forms is expected to be $\sim 1-2 \%$, resulting from the addition of the catalyst for the crosslinking reaction. Nevertheless, except for the fully fossil resin (resin A) and for the resin D for which essentially comparable bio-contents were measured in the liquid and in the solid, the other 2 samples gave very different results between the liquid and the solid. For the resins $\mathrm{F}$ and G, differences of $\sim 20$ and $\sim 10 \%$ were obtained between the liquid and the solid, with the estimated bio-content of the liquid always higher. This difference surely deserves more investigation, but we suspect that it can be explained by the evaporation of styrene from the liquid resin. 


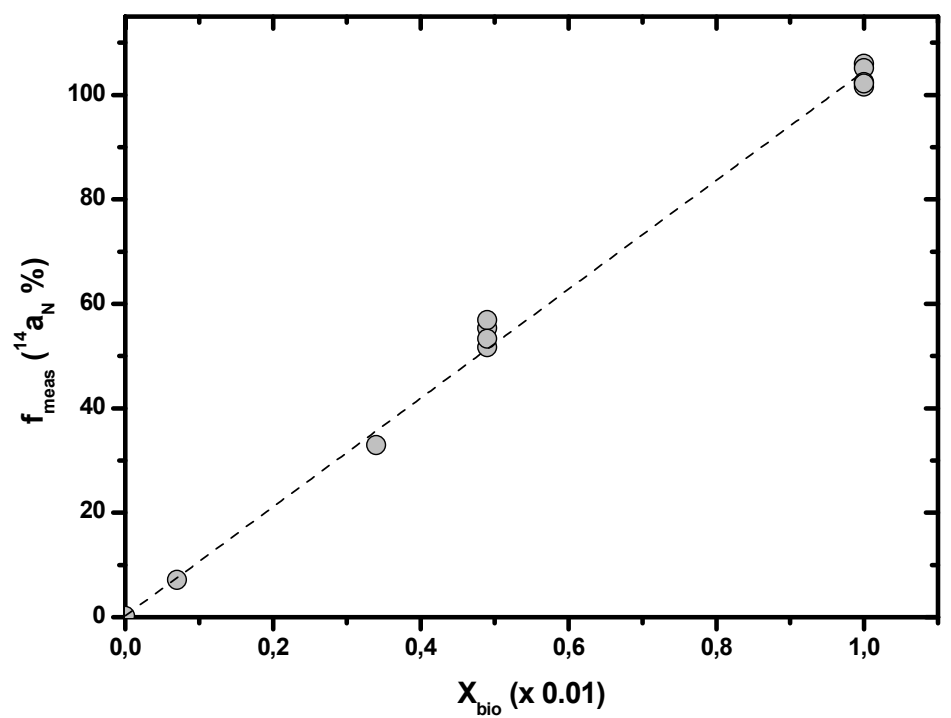

Figure 4 Measured ${ }^{14} \mathrm{C}$ concentration versus the expected bio-content for the solid resins and the fully biogenic raw materials.

As a further step, we also investigated the possible inhomogeneity within the same solid resin. For this reason, from resin $G$ the samples for analysis were taken at different depths from the external surface. The solidification process was carried out by putting the liquid resin in aluminum holders in order to obtain the solid resin as a disk with a diameter of $\sim 10 \mathrm{~cm}$ and a thickness of $\sim 1 \mathrm{~cm}$. From these solid resin disks, 3 samples were taken from the uppermost layer (1-2 mm from the surface), the inner part (in the middle of the disk) and the bottom of the disk. The results shown in Table 4 were surprising. For resin G, the measured bio-content of the uppermost samples was $89 \%$, significantly higher than the expected value (49\%), while the 2 samples taken in the middle and at the bottom showed values consistent with the expected values. In order to explain this effect, we considered 2 possibilities: the trapping of atmospheric $\mathrm{CO}_{2}$ in the uppermost layer, or the evaporation of a fossil volatile component (styrene). In order to test these hypotheses, we analyzed 2 samples taken at the surface and in the middle part of a fully fossil resin (resin A). For these samples, no difference was found between the 2 samples, suggesting that the effect noted for resin $\mathrm{G}$ cannot be explained by the absorption of atmospheric $\mathrm{CO}_{2}$, otherwise for the fossil resin this effect would have been even more visible. Furthermore, in order to justify the measured bio-content in the uppermost layer of resin $\mathrm{G}$ with the absorption of atmospheric air, more than $70 \%$ of the carbon in the uppermost layer should be derived from atmospheric $\mathrm{CO}_{2}$ and this seems unrealistic.

Table 4 Results of AMS analyses carried out on samples taken from different points to check the homogeneity of the measured bio-contents.

\begin{tabular}{llll}
\hline Sampling point & ${ }^{14} \mathrm{a}_{\mathrm{N}}$ or ${ }^{14} \mathrm{a}$ & $\delta^{13} \mathrm{C}(\% \mathrm{o})$ & Bio-content (measured) \\
\hline Surface & ${ }^{14} \mathrm{a}_{\mathrm{N}}=92.9 \pm 0.4$ & $-28.9 \pm 0.5$ & $89 \pm 1 \%$ \\
Middle & ${ }^{14} \mathrm{a}_{\mathrm{N}}=53.3 \pm 0.4$ & $-22.6 \pm 0.5$ & $51 \pm 1 \%$ \\
Bottom & ${ }^{14} \mathrm{a}_{\mathrm{N}}=54.0 \pm 0.4$ & $-22.9 \pm 0.5$ & $52 \pm 1 \%$ \\
Surface & ${ }^{14} \mathrm{a}=0.36 \pm 0.03$ & $-32.2 \pm 0.5$ & $0 \%$ \\
Middle & $14 \mathrm{a}=0.28 \pm 0.03$ & $-35.9 \pm 0.5$ & $0 \%$ \\
\hline
\end{tabular}




\section{G Quarta et al.}

Considering the obtained results, we thus think that the evaporation of styrene is responsible for the measured difference in the ${ }^{14} \mathrm{C}$ concentration. This suggests on one hand that one treat with caution the samples containing volatile components, but on the other hand, suggests a possible method to measure their release.

\section{CONCLUSIONS}

AMS ${ }^{14} \mathrm{C}$ analyses were carried out on unsaturated polyester resins produced from renewable raw materials in order to assess the potential of the method and its limitations for determination of the bio-fraction. Different resins were produced with different bio-fractions and analyzed together with the raw materials employed in the synthesis both of fossil and biogenic origin. The obtained results essentially confirm the high potential of the method. At the same time, the final uncertainty levels of $\sim 3 \%$ can be achieved by taking into account all the possible sources of uncertainty associated with the measurement and calculation of the bio-fraction. At the same time, it has been shown how the evaporation of volatile compounds can strongly influence the measured bio-fraction for both liquid and solid materials.

\section{ACKNOWLEDGMENTS}

We wish to thank Dr S W L Palstra, Centrum voor IsotopenOnderzoek (CIO), University of Groningen, the Netherlands, for helpful and fruitful discussions.

\section{REFERENCES}

Andjelkovic DD, Culkin DA, Loza R. 2009. Unsaturated polyester resins derived from renewable resources. Composites and Polycon. American Composites Manufacturers Association, USA.

ASTM International. 2010. Method D 6866-10: Standard test methods for determining the biobased content of solid, liquid, and gaseous samples using radiocarbon analysis. ASTM International, 100 Bar Harbor Drive, West Conshohocken, Pennsylvania, USA.

Calcagnile L, Quarta G, D'Elia M, Rizzo A, Gottdang A, Klein M, Mous DJW. 2004a. A new accelerator mass spectrometry facility in Lecce, Italy. Nuclear Instruments and Methods in Physics Research 223-224:1620

Calcagnile L, Quarta G, D'Elia M, Gottdang A, Klein M, Mous DJW. 2004b. Radiocarbon precision tests at the Lecce AMS facility using a sequential injection system. Nuclear Instruments and Methods Physics Research B 215(3-4):561-4.

Calcagnile L, Quarta G, D'Elia M. 2005. High-resolution accelerator-based mass spectrometry: precision, accuracy and background. Applied Radiation and Isotopes 62(4):623-9.

Calcagnile L, Quarta G, D'Elia M, Ciceri G, Martinotti W. 2011. Radiocarbon AMS determination of the biogenic component in $\mathrm{CO}_{2}$ emitted from waste incineration. Nuclear Instruments and Methods in Physics Research B 269(24):3158-62.

D'Elia M, Calcagnile L, Quarta G, Rizzo A, Sanapo C, Laudisa M, Toma U, Rizzo A. 2004. Sample preparation and blank values at the AMS radiocarbon facility of the University of Lecce. Nuclear Instruments and Methods in Physics Research B 223-224:278-83.

Dijs IJ, van der Windt E, Kaihola L, Van der Borg K. 2006. Quantitative determination by ${ }^{14} \mathrm{C}$ analysis of the biological component in fuels. Radiocarbon 48(3): 315-23.

Jahren AH, Saudek C, Yeung EH, Kao WHL, Kraft RA, Caballero B. 2006. An isotopic method for quantifying sweeteners derived from corn and sugar cane. American Journal of Clinical Nutrition 84(6):1380-4.

Levin I, Kromer B. 2004. The tropospheric ${ }^{14} \mathrm{CO}_{2}$ level in mid-latitudes of the Northern Hemisphere (19592003). Radiocarbon 46(3):1261-72.

Mook WG. 1980. The effect of fossil fuel and biogenic $\mathrm{CO}_{2}$ on the ${ }^{13} \mathrm{C}$ and ${ }^{14} \mathrm{C}$ content of atmospheric carbon dioxide. Radiocarbon 22(2):392-7.

Mook WG, van der Plicht J. 1999. Reporting ${ }^{14} \mathrm{C}$ activities and concentrations. Radiocarbon 41(3):227-39.

Norton GA. 2011. Interlaboratory variability of radiocarbon results obtained from blind AMS analyses on several modern carbon samples. Radiocarbon 53(3):5516.

Norton GA, Devlin SL. 2006. Determining the modern carbon content of biobased products using radiocarbon analysis. Bioresource Technology 97(16):208490.

Norton GA, Hood DG, Devlin SL. 2007. Accuracy of radioanalytical procedures used to determine the biobased content of manufactured products. Bioresource Technology 98(5):1052-6.

Onishi T, Ninomiya F, Kunioka M, Funabashi M, Ohara 


\section{Determination of Biobased Content in Plastics by ${ }^{14} \mathrm{C}$}

K. 2010. Biomass carbon ratio of polymer composites included biomass or petroleum origin resources. Polymer Degradation and Stability 95(8):1276-83.

Palstra SWL, Meijer HAJ. 2012. ${ }^{14} \mathrm{C}$-based determination of biogenic carbon fraction in fuels and flue gas $\mathrm{CO}_{2}$. Poster presented at the 21 st Radiocarbon conference, Paris, 9-13 July 2012.

Penczek P, Czub P, Pielichowski J. 2005. Unsaturated polyester resins: chemistry and technology. Advances in Polymer Science 184:1-95.

Pigati JS. 2002. On correcting ${ }^{14} \mathrm{C}$ ages of gastropod shell carbonate for fractionation. Radiocarbon 44(3):75560.

Quarta G, Calcagnile L, D'Elia M. 2004. The influence of injection parameters on mass fractionation phenomena in radiocarbon analysis. Nuclear Instruments and Methods in Physics Research B 217(4):644-8. 